\title{
Teores de ligninas, nitrogênio e taninos em folhas de espécies típicas do mangue
}

\author{
SILVANA A.P. DE GODOY ${ }^{1}$, MARCO A.S. MAYWORM ${ }^{1}$, VINCENT KURT LOํ, ANTONIO \\ SALATINO ${ }^{1}$ e YARA SCHAEFFER-NOVELLI ${ }^{2}$
}

(recebido em 20/09/95; aceito em 30/08/96)

\begin{abstract}
Contents of lignins, nitrogen and tannins in leaves of typical species of mangroves). The contents of lignins, total N and tannins were measured in leaves of Avicennia schaueriana, Laguncularia racemosa and Rhizophora mangle. The leaves were collected in mangrove areas of Suape, Madre de Deus island (a highly polluted site in Bahia), Cananéia and two localities of Bertioga, one of them with high levels of pollution, in which no individuals of Rhizophora occur, and the other being an area adjacent to the latter. The leaves of Laguncularia and Rhizophora contain high contents of tannins, the former presenting from three to four times as much tannins as the latter. Leaves of Avicennia are devoid of tannins and possess the highest contents of $\mathrm{N}$. The contents of lignins increase in general along the sequence Avicennia $<$ Laguncularia $<$ Rhizophora. The contents of $\mathrm{N}$, for all species, were practically the same, comparing the samples from Suape and Cananéia. However, the leaves from Bertioga presented higher levels, which reached a maximum in samples from the most polluted area. The leaves of Laguncularia and Rhizophora collected in Suape presented less tannins and more lignins than the samples from Cananéia. The contents of tannins of the leaves of Laguncularia were higher in the samples of Bertioga than those of Cananéia, but the opposite is observed in Rhizophora. The amount of tannins in leaves of Laguncularia from Madre de Deus were the lowest among the localities investigated. The contents of lignins seem to be strongly influenced by pollution, a regular decrease being observed along the series Cananéia>Bertioga/adjacent area>Bertioga/polluted area. It seems that the levels of $\mathrm{N}$ and lignins are affected by pollution, the former assuming higher values in polluted areas and the latter lower values. The leaves of Laguncularia from Madre de Deus presented also relatively low levels of lignins, probably as a consequence of environmental impact. A possibility is raised that a decrease in the production of lignins may be one of the reasons for the replacement of Rhizophora by Laguncularia in the most polluted areas.
\end{abstract}

RESUMO - (Teores de ligninas, nitrogênio e taninos em folhas de espécies típicas de mangue). Mediram-se os teores de ligninas, N total e taninos em folhas de Avicennia schaueriana, Laguncularia racemosa e Rhizophora mangle, coletadas em manguezais de Suape, Ilha Madre de Deus (um local muito poluído na Bahía), Cananéia e duas localidades de Bertioga, uma delas fortemente impactada por descargas poluentes, na qual não se observam indivíduos de Rhizophora, e outra situada à margem desta última área. Verificou-se que as folhas de Laguncularia e Rhizophora contêm altos teores de taninos, sendo as da primeira espécie três a quatro vezes mais ricas que as da última. As folhas de Avicennia apresentaram-se desprovidas de taninos e com os mais altos teores de N. Os teores de ligninas em geral crescem na sequiência Avicennia < Laguncularia <Rhizophora. Entre as amostras de Suape e Cananéia, os teores de N não diferiram muito para as três espécies. Porém, as folhas provenientes de Bertioga apresentaram teores mais elevados, atingindo valores extremos na zona mais impactada. As folhas de Laguncularia e Rhizophora coletadas em Suape apresentaram menos taninos e mais ligninas que as folhas obtidas em Cananéia. A dosagem de taninos para as folhas de Laguncularia é maior nas amostras de Bertioga do que de Cananéia, o inverso ocorrendo em Rhizophora. A dosagem de taninos na amostra de Laguncularia proveniente de Madre de Deus apresentou o valor mais baixo entre todas as localidades pesquisadas. Os teores de lignina parecem ser fortemente influenciados pela poluição, observando-se um decréscimo regular na série Cananéia>Bertioga/área limítrofe>Bertioga/área impactada. Aparentemente, os teores de $\mathrm{N}$ e ligninas são afetados pela poluição, os primeiros assumindo valores mais altos em locais poluídos, e os últimos, valores mais baixos. Também a amostra de Laguncularia proveniente de Madre de Deus apresentou teor muito pequeno de ligninas, possivelmente devido ao impacto ambiental. Aventa-se a possibilidade de que a redução na produção de ligninas possa ser uma das causas para a substituição de Rhizophora por Laguncularia em locais fortemente impactados por poluição.

Key words - Mangrove, Avicennia, Laguncularia, Rhizophora, tannins, lignins

\section{Introdução}

Os manguezais constituem comunidades vegetais muito conhecidas por sua riqueza em taninos (ver p.ex. Janzen 1974). Rizzini \& Mors (1976) comentam que Rhizophora mangle,

1. Departamento de Botânica, Instituto de Biociências, Universidade de São Paulo, Caixa Postal 11461, 05422970 São Paulo, SP, Brasil.

2. Instituto Oceanográfico, Universidade de São Paulo, Caixa Postal 66149, 05508-900 São Paulo, SP, Brasil conhecida por mangue-vermelho, pode apresentar até $40 \%$ de taninos catequínicos na casca, um teor equivalente ao da acácia-negra, ou "wattle" (Acacia decurrens), considerada a planta tanífera mais importante do mundo. Além do mangue-vermelho, o mangue-branco (Laguncularia racemosa) é também espécie dos manguezais fornecedora de taninos. Os mencionados autores comentam ainda que os manguezais constituem "a maior reserva de tanino do mundo". É precisamente a riqueza em taninos com alto valor comercial, em alguns de seus representantes dominantes, que vem sendo uma das 
causas do extrativismo predatório nos ambientes de mangue no Brasil, desde os tempos coloniais, como atesta o Alvará com força de lei, exarado em 1760. Outro problema que vem afetando, em escala crescente, as comunidades de manguezais ao longo da costa brasileira é o da poluição, especialmente por derramamento de óleo.

Apesar da importância dos manguezais, que contam com espécies de valor comercial pelo seu conteúdo em taninos, praticamente não se dispõe de estudos sobre o teor de taninos em outras partes da planta, como as folhas, apesar de estes órgãos serem os mais importantes do ponto de vista metabólico. Também pouco ou nada se sabe sobre a variação do teor de taninos entre localidades distintas da costa brasileira e sobre a influência do impacto ambiental.

As interrelações das vias bioquímicas no metabolismo vegetal prevêem uma competição, por precursores fenilpropanóides, entre a síntese de taninos e a de ligninas, dois grupos expressivos de metabólitos secundários fenólicos (Mann 1987). Por outro lado, o metabolismo fenólico como um todo é mantido em equilíbrio com o metabolismo do nitrogênio, através da PAL (fenilalanina-amônia-liase) e da TAL (tirosina-amônia-liase), que catalisam, respectivamente, as interconversões fenilalanina $\leftrightarrow$ ácido cinâmico e tirosina $\leftrightarrow$ ácido $p$-cumárico (Hanson \& Havir 1981). Por essa razão, muitos fatores de estresse que afetam o metabolismo protéico têm um impacto considerável sobre o metabolismo fenólico (Margna 1977, Gershenzon 1984).

O presente trabalho teve por objetivo verificar o teor de taninos foliares de três importantes espécies arbóreas dos manguezais brasileiros: Avicennia schaueriana, Laguncularia racemosa e Rhizophora mangle. O trabalho teve ainda três propósitos adicionais: a) comparar os teores de taninos foliares de amostras da mesma espécie coletadas em locais distintos do litoral; b) dosar os teores de ligninas das folhas, uma vez que estas, a exemplo dos taninos, constituem importantes componentes do metabolismo fenólico; c) dosar os teores de nitrogênio foliar total, que reflete o teor de proteínas. Os resultados poderão ser úteis para o melhor entendimento da fisiologia das plantas do mangue e da ecologia dos manguezais.

\section{Material e métodos}

Folhas adultas, correspondentes ao terceiro par, foram coletadas de indivíduos de Avicennia schaueriana Stapf \& Leechman, Laguncularia racemosa Gaertn. e Rhizophora mangle L. As folhas foram obtidas em áreas de manguezal em Bertioga (SP) e Cananéia (SP). As folhas provenientes de Cananéia correspondem a três indivíduos distintos para cada espécie, enquanto as de Bertioga correspondem a seis indivíduos de Avicennia e seis de Laguncularia, sendo três deles (para cada espécie) localizados em área fortemente impactada por poluição (inclusive com derramamento de óleo ocorrido em outubro de 1983) e denominada localmente por "lixão" do Iriri, e três outros situados em área limítrofe a essa zona. Como não ocorre mais Rhizophora na área do "lixão", devido ao impacto do derramamento de óleo, as amostras dessa espécie correspondentes a Bertioga restringem-se a três indivíduos, todos da área limítrofe. Foram ainda obtidas no manguezal desse último município duas amostras de folhas senescentes de Laguncularia, uma na área do "lixão" e outra na zona limítrofe, além de uma amostra de folhas senescentes de Rhizophora, coletada na zona limítrofe à área mais poluída por petróleo e chorume do lixão. Em Suape (PE), foram coletadas folhas de Avicennia e Laguncularia correspondentes a um indivíduo, além de folhas de três plantas de Rhizophora. Finalmente, coletaram-se folhas de um indivíduo de Laguncularia na Ilha Madre de Deus, Baía de Todos os Santos (BA). O manguezal na Ilha Madre de Deus é uma área fortemente impactada, inclusive com freqüentes derramamentos de óleo.

As folhas foram secas à temperatura ambiente, no escuro. Todas as dosagens foram realizadas em triplicatas de uma mesma amostra. Os teores de nitrogênio total foram determinados pelo método micro-Kjeldahl. Usou-se o método de Hagerman (1987) da difusão radial em agarose para a dosagem de taninos, empregando-se ácido tânico (Merck) como referência. Os teores de lignina foram determinados segundo o método ABCP M 10/71 do Instituto de Pesquisas Tecnológicas, alterando-se o tempo de digestão ácida de duas para quatro horas. Em síntese, o método consistiu numa extração com etanol em soxhlet do material finamente dividido, e em seguida com mistura etanol:tolueno (1:1). O resíduo é lavado com etanol e posteriormente tratado com água quente. Finalmente, foi feita uma digestão com ácido sulfúrico $72 \%$ durante quatro horas a $19^{\circ} \mathrm{C}$, sendo o resíduo lavado, seco e pesado.

\section{Resultados}

Os teores de $\mathrm{N}$ total, taninos e ligninas de amostras de Avicennia, Laguncularia e Rhizophora, procedentes das várias localidades, acham-se expressos na tabela 1. Todos os dados correspondem à média de três dosagens. A maior parte das análises foi conduzida em três amostras independentes. Com número de amostras $n=3$, praticamente não é possível avaliarem-se as diferenças observadas em termos estatísticos. Os dados apresentados são, no entanto, indicativos de tendências que aparentemente se cristalizariam em feições estatisticamente significativas, caso se dispusessem de amostragens suficientemente grandes. 
As folhas de Laguncularia e Rhizophora apresentam altos teores de taninos. Contudo, as folhas de Avicennia forneceram extratos desprovidos de componentes que precipitam com albumina de soro bovino (tabela 1 ). $\mathrm{O}$ teor de $\mathrm{N}$ total é maior nas folhas de Avicennia, em comparação a Laguncularia e Rhizophora (tabela 1). No que se refere ao teor de ligninas, nas amostras provenientes de Suape e Cananéia, os teores aumentam na seqüência Avicennia $>$ Laguncularia $>$ Rhizophora. Porém, as amostras procedentes de Bertioga apresentaram teores de lignina iguais ou um pouco inferiores aos de Avicennia.

O confronto dos resultados da tabela 1 , referentes aos teores de $\mathrm{N}$, taninos e ligninas de amostras da mesma espécie, mas coletadas em localidades distintas, revela que, em certos casos, não há diferenças notáveis, mas em outros há alterações evidentes, algumas delas bem acentuadas. Para as três espécies, o teor de $\mathrm{N}$ parece não diferir no confronto entre as amostras procedentes de Suape e Cananéia. No entanto, as amostras de Bertioga mostram uma nítida tendência a teores mais elevados, em particular as folhas de Avicennia e Laguncularia coletadas na área do "lixão" (a população de Rhizophora não se recompôs nesse ambiente, após o derramamento de óleo). Nas amostras de Suape, tanto de Laguncularia quanto de Rhizophora, os teores de taninos são bem inferiores aos daquelas coletadas no estado de São Paulo. Há, no entanto, uma nítida variação intraespecífica nos teores de taninos, quando se comparam as amostras de Cananéia e Bertioga: as amostras de Laguncularia provenientes de Bertioga apresentam

Tabela 1. Teores percentuais, com base no peso seco, de $\mathrm{N}$ total, ligninas e taninos de folhas adultas não senescentes e senescentes de Avicenia schaueriana Stapf \& Leechman (A), Laguncularia racemosa Gaert (L) e Rhizophora mangle L. (R) de várias localidades da costa brasileira.

\begin{tabular}{|c|c|c|c|c|c|c|c|c|c|}
\hline \multirow{2}{*}{ Localidade } & \multicolumn{3}{|c|}{ Nitrogênio } & \multicolumn{3}{|c|}{ Ligninas } & \multicolumn{3}{|c|}{ Taninos } \\
\hline & A & $\mathrm{L}$ & $\mathrm{R}$ & A & $\mathrm{L}$ & $\mathrm{R}$ & A & $\mathrm{L}$ & $\mathrm{R}$ \\
\hline SUAPE & 2,2 & 1,6 & 1,5 & 18,8 & 23,4 & 28,6 & - & 13,8 & 2,8 \\
\hline \multirow[t]{2}{*}{ (não impactada) } & $*$ & $*$ & 1,4 & $*$ & $*$ & 29,4 & $*$ & $*$ & $*$ \\
\hline & $*$ & $*$ & 1,1 & $*$ & $*$ & 28,9 & $*$ & $*$ & $*$ \\
\hline \multirow{3}{*}{$\begin{array}{l}\text { CANANÉIA } \\
\text { (não impactada) }\end{array}$} & 2,1 & 1,4 & 1,4 & 14,9 & 21,2 & 24,5 & - & 23,2 & 8,3 \\
\hline & 2,2 & 1,3 & 1,4 & 16,8 & 19,1 & 25,4 & - & 24,7 & 8,7 \\
\hline & 1,8 & 1,4 & 1,6 & 15,1 & 20,0 & 25,9 & - & 20,8 & 7,2 \\
\hline $\begin{array}{l}\text { ILHA MADRE DE DEUS } \\
\text { (impactada) }\end{array}$ & $*$ & 1,4 & $*$ & $*$ & 10,3 & $*$ & $*$ & 10,6 & $*$ \\
\hline \multicolumn{10}{|l|}{ BERTIOGA } \\
\hline \multicolumn{10}{|l|}{ Área limítrofe } \\
\hline \multirow[t]{3}{*}{ Folhas não senescentes } & 2,1 & 1,5 & 1,9 & 10,9 & 9,7 & 13,8 & - & 33,2 & 7,0 \\
\hline & 2,9 & 1,8 & 1,9 & 8,1 & 9,5 & 15,1 & - & 25,2 & 6,8 \\
\hline & 2,3 & 1,5 & 2,0 & 10,5 & 8,9 & 17,8 & - & 33,0 & 7,0 \\
\hline Folhas senescentes & $*$ & 0,8 & 0,8 & $*$ & 10,1 & 15,2 & - & 14,5 & 6,7 \\
\hline \multicolumn{10}{|l|}{ Área impactada } \\
\hline \multirow[t]{3}{*}{ Folhas não senescentes } & 3,3 & 1,8 & $*$ & 8,4 & 8,8 & $*$ & - & 31,5 & $*$ \\
\hline & 3,1 & 2,2 & $*$ & 7,9 & 6,1 & $*$ & - & 30,7 & $*$ \\
\hline & 2,8 & 2,2 & $*$ & 8,9 & 6,5 & $*$ & - & 31,0 & $*$ \\
\hline Folhas senescentes & $*$ & 0,6 & $*$ & $*$ & 9,3 & $*$ & - & 19,2 & $*$ \\
\hline
\end{tabular}

*: Dosagem não realizada; -: não detectado 
um teor mais elevado que as de Cananéia, enquanto que para as amostras de Rhizophora parece ocorrer o oposto. Aparentemente, o teor de taninos em Laguncularia não varia entre as duas áreas pesquisadas de Bertioga. Enquanto os teores de taninos das amostras do estado de São Paulo são nitidamente superiores às de Suape, os teores de ligninas são maiores nas amostras desse município, sendo a observação válida para as três espécies. A amostra de Laguncularia proveniente da Ilha Madre de Deus forneceu um baixo teor de taninos, em comparação até com as amostras de Suape; quanto ao teor de ligninas, o dado obtido é aproximadamente a metade do que se encontrou nas amostras da mesma espécie coletadas em Suape e Cananéia e comparável aos resultados obtidos com as amostras de Bertioga. A comparação entre os teores de ligninas das amostras de Cananéia e Bertioga, para as três espécies, revela valores bem inferiores nas amostras da última localidade. Parece haver também uma diferença entre os teores de ligninas nas amostras das duas localidades de Bertioga, observando-se valores inferiores na zona mais poluída, uma tendência que é mais nítida nas amostras de Laguncularia. As folhas senescentes coletadas em Bertioga mostraram teores de $\mathrm{N} \mathrm{e}$ taninos inferiores aos das folhas não senescentes; os teores de ligninas são superiores aos das folhas não senescentes da mesma espécie.

\section{Discussão}

As substâncias fenólicas constituem um complexo de metabólitos secundários extremamente diversificado (Harborne 1988). Os taninos constituem uma classe de substâncias fenólicas muito heterogênea quanto aos aspectos estruturais (Martin \& Martin 1983). O reconhecimento dos taninos como grupo é feito por meio de um critério técnico, qual seja a propriedade que eles possuem de converter pele animal em couro impermeável e imputrescível (Haslam 1988). Tal propriedade se deve à capacidade dos taninos de se combinar de modo praticamente irreversível com proteínas e outros biopolímeros, advindo daí as suas conhecidas propriedades adstringentes. Devido à falta de uma definição precisa, não tem sido possível estabelecer-se um método que determine a quantidade exata de taninos num tecido vegetal.
Contudo, os métodos disponíveis são úteis para fins comparativos. O método de Hagerman (1987) tem, entre outros, o mérito de ser baseado numa propriedade dos taninos na qual se fundamenta a sua própria definição, ou seja a capacidade que eles possuem de precipitar proteínas. A conveniência da introdução de métodos que avaliem a capacidade dos taninos de precipitar proteínas foi realçada por Martin \& Martin (1983).

Apesar de observar-se uma distribuição muito ampla de taninos nas angiospermas, há uma preferência para a ocorrência desses polifenóis em certos grupos de plantas, principalmente nos taxa lenhosos de Hamamelidae, Rosidae e Dilleniidae (sensu Cronquist 1981). Gardner (1977) chama atenção para os aspectos evolutivos da perda de taninos na transição Rosidae-Asteridae. Os resultados do presente trabalho refletem essa tendência, devido à ausência de taninos em $A$. schaueriana (uma espécie de Verbenaceae, subclasse Asteridae) e a presença maciça dessas substâncias em L. racemosa (Combretaceae, subclasse Rosidae) e $R$. mangle (Rhizophoraceae, subclasse Rosidae ).

Um fato reconhecido já há algum tempo é a relação negativa entre o teor de nitrogênio (proteínas) e o teor de substâncias fenólicas foliares. Plantas que absorvem rapidamente os nutrientes disponíveis tendem a apresentar maiores teores de proteínas e menor quantidade de substâncias fenólicas nas folhas (Chapin 1980). Ao contrário, plantas adaptadas a ambientes pobres em nutrientes têm crescimento lento, baixos teores de proteínas e altos conteúdos de substâncias fenólicas, apresentando ainda tendência à esclerofilia. É o caso típico das plantas de cerrado (Arens 1958, Salatino 1993). Gershenzon (1984) relaciona numerosos experimentos que demonstram a tendência ao acúmulo de substâncias fenólicas em plantas submetidas a condições de estresse. O manguezal não pode ser qualificado como um ambiente tipicamente oligotrófico. O elevado teor de taninos em certos representantes lenhosos do manguezal poderia ser explicado pelo alto teor salino na água e no sedimento, o que submeteria as plantas a um estresse fisiológico; este condicionaria um crescimento lento que, por seu turno levaria a uma seleção de linhagens adaptadas a um acúmulo elevado de metabólitos secundários, principalmente 
de natureza fenólica (Coley et al. 1985). O elevado teor de taninos foliares em representantes do manguezal poderia ser benéfico a toda a comunidade vegetal do ecossistema, na medida em que essas substâncias retardam a decomposição da serapilheira (Zucker 1983). Dessa forma, os taninos acabam contribuindo para que haja uma provisão regular, ainda que lenta, de nutrientes para as plantas (Adaime 1985). A importância disso é realçada no caso do manguezal, dado o caráter altamente drenável do seu substrato, assim como sua exposição às águas das preamares.

São notáveis as diferenças, principalmente no teor de ligninas e taninos, entre as plantas da mesma espécie, coletadas em locais diferentes da costa brasileira (tabela 1). Não é possível, até o momento, atribuir-se tais diferenças a aspectos genéticos ou ambientais. No caso das plantas de Cananéia e Bertioga, com grande probabilidade as diferenças observadas são devidas a aspectos ambientais, resultantes principalmente da poluição. Ao se compararem os teores de $\mathrm{N}$, observa-se uma tendência constante de incremento dos valores para todas as espécies, quando se confrontam as amostras de Cananéia com as de Bertioga/área limítrofe e as de Bertioga/“lixão". Em princípio, seria esperada uma redução no teor de taninos foliares com o acréscimo no teor de N. No caso de Rhizophora, realmente parece ser essa a tendência, mas o mesmo não se pode dizer em relação a Laguncularia. Quanto ao teor de ligninas, o que se observa é uma diminuição gradativa nos teores, quando se comparam as três localidades acima mencionadas para o estado de São de Paulo. Parece fora de dúvida que as condições de poluição estabelecidas no litoral Sul do estado de São Paulo afetam a produção de metabólitos secundários das plantas do mangue, entre eles as ligninas. Provavelmente, o mesmo ocorre com a população de Laguncularia na Ilha Madre de Deus. Uma vez que tais substâncias são fundamentais para a biologia das plantas, o prejuízo na sua produção possivelmente é um dos aspectos que põem em risco a ocorrência das espécies em determinados locais, levando até ao desaparecimento de algumas delas, como é o caso de Rhizophora na área do "lixão" de Bertioga. Anteriormente ao derramamento de óleo, Rhizophora mangle dominava o bosque do qual foram obtidas as amostras de Laguncularia racemosa ("lixão "). É interessante notar-se que essa última espécie é a que apresenta o maior teor de ligninas foliares, o que leva à suposição de que a redução do teor dessas substâncias abaixo de um dado valor implica em sério prejuízo à subsistência dos indivíduos. Essa observação ajuda a explicar a sua inexistência na área do "lixão". Um dado da tabela 1 de difícil interpretação é o valor extremamente baixo de taninos da amostra de Laguncularia proveniente da Ilha Madre de Deus. Tal valor é próximo daquele encontrado para a amostra de Suape. No entanto, os dois locais diferem muito do ponto de vista ambiental. A alta incidência de galhas, alterando de modo acentuado a fisiologia e o metabolismo dos tecidos vegetais, poderia ser uma outra explicação para os baixos teores de taninos e ligninas observados nas folhas de Laguncularia provenientes da Ilha Madre de Deus.

Os dados da tabela 1 permitem concluir com alguma segurança que dois parâmetros são sujeitos às condições ambientais nos locais em que as amostras foram coletadas: a) o teor de N, pelo menos no que se refere às amostras do estado de São Paulo, com uma nítida tendência para valores mais altos em áreas impactadas; b) o teor de ligninas, com uma forte tendência para valores mais baixos com o impacto ambiental, a ponto, possivelmente, de se tornar limitante para a sobrevivência da espécie em locais muito poluídos.

Os valores de $\mathrm{N}$, taninos e ligninas obtidos nas amostras de folhas senescentes, quando comparados aos das folhas não senescentes, seguem uma tendência previsível. As amostras de folhas senescentes obtidas nas duas localidades de Bertioga apresentaram teores de $\mathrm{Ne}$ taninos inferiores aos das folhas não senescentes (tabela 1). No caso do N, sabe-se que ele é mobilizado nas fases que antecedem imediatamente o processo de abscisão das folhas; além disso, as proteínas e outros derivados nitrogenados são rapidamente decompostos por microrganismos do solo. No caso dos taninos, tratam-se de substâncias fenólicas que se oxidam facilmente, perdendo nesse processo a sua atividade adstringente. Já as ligninas são polímeros altamente resistentes à decomposição, o que explica o aumento relativo de sua quantidade nas folhas senescentes.

Agradecimentos - Os autores são gratos ao CNPq (Conselho Nacional do Desenvolvimento Científico e Tecnológico) pela concessão de bolsas durante a realização do presente trabalho. 


\section{Referências bibliográficas}

Adaime, R.R. 1985. Produção do bosque de mangue da Gamboa Nóbrega (Cananéia, 25 ${ }^{\circ}$ Lat S -Brasil) Tese de doutorado, Universidade de São Paulo, Instituto Oceanográfico.

Arens, K. 1958. Considerações sobre as causas do xeromorfismo foliar Bol. Fac. Fil. Ciênc. Letr. Univ. São Paulo, 224, Botânica 15:25-56.

Chapin, F.S. 1980. The mineral nutrition of wild plants. Annu. Rev. Ecol. Syst. 11:233-260.

Coley, P.D., Bryant, J.P. \& Chapin, F.S 1985. Resource availability and plant antiherbivore defense. Science 230:895-899.

Cronquist, A. 1981. An integrated system of classification of flowering plants. Columbia University Press, New York.

Gardner, R. 1977. Systematic distribution and ecological function of the secondary metabolites of the Rosidae-Asteridae. Biochem. Syst. Ecol 5:29-35.

Gershenzon, J. 1984. Changes in the levels of plant secondary metabolite production under water and nutrient stress. Recent Adv. Phytochem. 18:273-320.

Hagerman, A.E. 1987. Radial diffusion method for determining tannin in plant extracts. J. Chem. Ecol. 13:437-449.

Hanson, K.R. \& Havir, E. A. 1981. Phenylalanine ammonia-lyase. In The biochemistry of plants, vol. 7, Secondary plant products (E.E. Conn, ed.). Academic Press, New York p. $577-626$.

Harborne, J.B. 1988. General procedures and measurement of total phenolics. In Methods in plant biochemistry (P.M. Dey \& J.B. Harborne, eds.). Academic Press, London, p. 1-28.

Haslam, E. 1988. Plant polyphenols (syn. vegetable tannins) and chemical defense - a reappraisal. J. Chem. Ecol. 14:1789-1805.

Janzen, D.H. 1974. Tropical blackwater rivers, animals and mast fruiting by the Dipterocarpaceae. Biotropica 6:69-103.

Mann, J. 1987. Secondary metabolism. Clarendon Press, Oxford.

Margna, U. 1977. Control at the level of substrate supply: an alternative in the regulation of phenylpropanoid accumulation in plant cells. Phytochemistry 16:419-426.

Martin, J.S. \& Martin, M.M. 1983. Tannin assays in ecological studies. Precipitation of ribulose-1,5-biphosphate carboxylase/oxygenase by tannic acid, quebracho and oak leaf foliage extracts. J. Chem. Ecol. 9:285-294.

Rizzini, C.T. \& Mors, W.B., 1976. Botânica econômica brasileira. E.P.U. e EDUSP, São Paulo.

Salatino, A. 1993. Chemical ecology and the theory of oligotrophic scleromorphism. An. Acad. bras. Ci. 65:1-13.

Zucker, W.Z. 1983. Does structure determine function? An ecological perspective. Am. Nat. 121:335-365. 